\title{
Promoting Student-Run Online Class Review Activities as Effective Cooperative Learning
}

\author{
Kanong Ruttanokorn, Paiboon Nuntanakorn, Sarayut Janmahasatian, Theerasak Rojanarata*
}

Faculty of Pharmacy Silpakorn University, Nakhon Pathom, THAILAND.

\begin{abstract}
Objectives: The aim of this work was to enable students to set up and organize for themselves online review activities after class. Materials and Methods: Students worked as groups to create short notes and quizzes that covered the topics from a lecture course and shared them by using free online tools. To provide support and motivation, the instructors offered advice on how to organize the activities and effectively create quizzes and notes. Prizes were awarded to students who won the popular votes for the best short notes and some students' quizzes were incorporated into the end of course exam. After the activities, the students' opinions and levels of satisfaction were surveyed. Results: The students generated, submitted for evaluation, revised and then shared class review materials on a website operated by students themselves. After being improved through instructor's assessment, the quizzes and short notes were well received and used by students, resulting in a higher average exam score with a lower variance than that in the previous year in which these activities were not conducted. The students reported that they were satisfied with the activities, had a positive attitude towards them and perceived their benefits. Furthermore, they understood the process of how to produce online review activities and were confident that they could transfer their experiences to set up similar activities in other courses. Conclusion: By giving students the opportunity of learning how to run lesson review activities online and providing them with appropriate supports, learning can be shifted from a teacher-organized task to a student-run activity, providing an effective means of cooperative learning.
\end{abstract}

Key words: Student-run, Review activity, Online, Quiz, Notes, Cooperative learning.

\section{INTRODUCTION}

Reviewing lessons is an essential part of learning and a powerful technique which helps students to reengage with the information that they have learned in class by allowing them to process, organize, integrate and remember the contents more efficiently and effectively. Traditionally, students may have read lecture handouts or practiced exercises provided by instructors to review lessons after class. However, in recent years, the goal of education has shifted to one which encourages students to actively participate in the entire educational process. ${ }^{1,2}$ Active learning is recognized as an effective means of achieving this goal..$^{3-5}$ Among a variety of active learning approaches which promote lesson review activities, one is to have students generate a set of review materials based on their prior instruction in class. ${ }^{6-11}$ After being generated, the contents are usually reviewed by instructors and shared with other students. To generate questions, students are required to identify relevant and important content they have learned and to formulate questions around this, thereby leading to improved and deeper learning as well as effective questioning abilities. ${ }^{12,13}$ In a similar way, having students generate short notes enhances students' comprehension of the materials and enables them to develop skills necessary to identify and extract key points of the contents. Producing well organized and informative notes with attractive designs also encourages creativity. For instructors,
Submission Date: 10-02-2020; Revision Date: 29-05-2020; Accepted Date: 07-10-2020

DOI: 10.5530/ijper.54.4.185 Correspondence: Dr. Theerasak Rojanarata Associate Professor, Department of

Pharmaceutical Chemistry, Faculty of Pharmacy,

Silpakorn University, Nakhon Pathom-73000, THAILAND.

Phone no: +66-34-255800

Email id: rojanarata_t@

su.ac.th

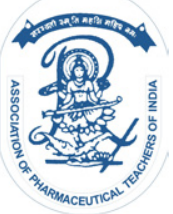

www.ijper.org 
student-generated review materials assist in evaluating the level of students' knowledge and in revealing issues which students misunderstand, providing opportunities for giving feedback. ${ }^{14}$

Today, students are familiar with using digital technologies in everyday life and find them extremely attractive. As a result, efforts have been made to set up educational activities on an online platform. For example, Weblogs and Wikis are useful authoring tools for students to write and share ideas. ${ }^{15}$ Online virtual whiteboards promote collaborative activities such as brainstorming and remote discussions. ${ }^{16}$ In many studies it has been found that when online tools or mobile technologies are incorporated to studentgenerated questions, it can further enhance students' interest, motivation and engagement by offering the opportunity for 'anytime and anywhere' learning., ${ }^{3,8,10}$

Although it appears to be an effective method of learning, the traditional role of students who participate in the review activities is usually limited to producing the contents whilst the responsibility for setting up and running the activities still lies with the teachers. As a result, students are not given the chance to develop the skills necessary to set up and operate such activities themselves for use in other courses. As the proverb says "give a man a fish and you feed him for a day; teach a man to fish and you feed him for a lifetime", the aim of this work was to move away from the traditional teacher-centered pedagogical model to one where students are given responsibility for organizing review activities themselves. It was anticipated that this approach would not only improve the learning effectiveness in the course where the activities were conducted in the present work, but can also be transferred for use in setting up the review activities by students themselves in other courses.

\section{MATERIALS AND METHODS}

The activities were conducted in the Fundamentals in Pharmaceutical Chemistry course (1-credit) for secondyear pharmacy students in 2018 at Silpakorn University, Thailand. This subject is the first pharmaceutical chemistry course of the curriculum containing 13 lecture topics taught by 5 lecturers. Before the opening of the semester, the instructor prepared a draft weblog (https://fpcpharmsu.blogspot.com) to be used for posting student-generated summary notes and quizzes as well as being a means of communication between students and teachers. Supporting information e.g. suggestions on how to write good multiple choice questions (MCQs), technical guidelines for using Flip snack and Google Form to create and share short notes and quizzes online and the instructor evaluation forms were prepared and deposited on the blog as electronic files or links for convenient access. The timeline for each activity was set and announced on the blog.

When the course started, the participants consisting of 158 students enrolled on the course and the 14 academic staff that played roles as lecturers or reviewers were informed about the activities and all of them agreed to join the activities. Students were then divided into groups of 5-6.

As shown in Figure 1, the student performed several activities with support from instructors. To enable the students to run the activities, all of them were advised to study the suggestions about the activities from electronic documents or links to useful websites. In addition, 15 volunteer students were trained in a two-hour workshop about weblog usage in order to work as blog administrators. They were authorized to manage or modify the blog through such as adding/ editing pages or menus. Each week, after the lecture had finished, three groups independently created one informative and captivating summary and three MCQ items on the same topic and completed the tasks within the 3-day deadline. Prior to being released to classmates, these materials were sent via email to the instructors for evaluation based on e.g. the relevance to the main contents and learning objectives, the accuracy of answers as well as the clarity of language. Once the evaluation was completed, usually within 3 days, comments and suggestions were sent to the students. After that, the students took responsibility to revise and then share the short notes and quizzes on the blog as flipbooks and online quizzes, respectively, within 2 days. Once the material was shared online, all students

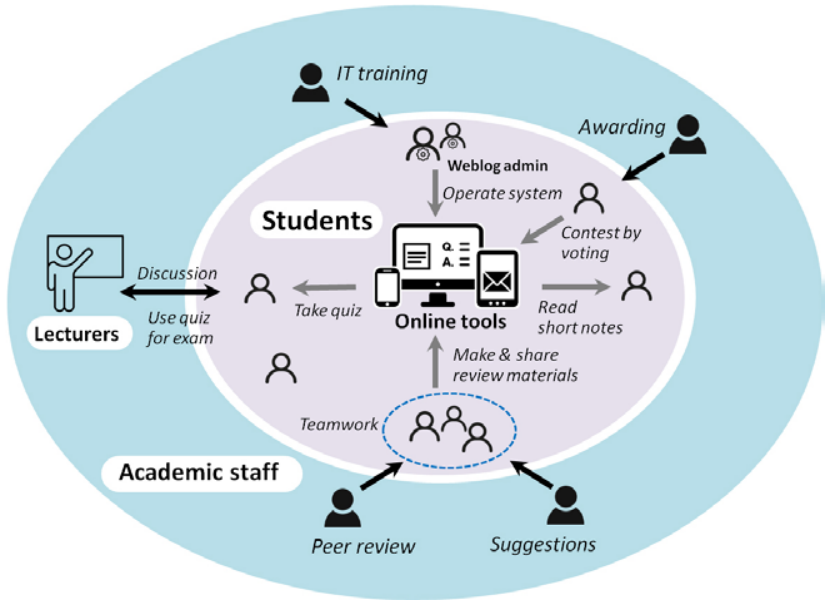

Figure 1: Student-run online review activities and appropriate support from the instructors. 
had unlimited access to all the contents including notes and quizzes which they could take as many times as they wanted during the remainder of the course. Quiz scores were instantly reported online after the answers were submitted and did not count for course grading. To encourage participation, students were invited to vote for one favorite summary note in each topic via an online voting system (Google Forms) and the winners were announced in the hall of fame session on the blog and prizes were awarded in the classroom. In addition, about $10 \%$ of student-generated quizzes were selected by the lecturers and incorporated into the course examination. Nevertheless, the students were not promised that the examination would contain questions from the bank they built. It should also be noted that throughout the semester-long activities, students and lecturers could communicate with each other via open discussion on the blog or by direct e-mail.

The average exam scores of the students who completed this course $(n=158)$ were compared with those in the previous year (2017) in which no class online review activities were carried out $(n=162)$. In addition, online questionnaires were used to survey students' and teachers' levels of satisfaction and opinions towards the activities. Approval for this study was obtained from the Institutional Review Board.

\section{RESULTS}

The students were capable of running activities i.e. generating review materials and then submitting them for appraisal as well as editing and finally posting them on the weblog. An example of their work is illustrated in Figure 2. From the survey (156 responders), 88.5\% of them answered that they participated in making summary notes and quizzes at a high to very high level. In addition, $98.7 \%$ of them had read notes and 100\% had taken quizzes in at least one topic. According to the statistics of quiz usage tracked by Google Forms, 101 of 158 students $(63.9 \%)$ took the quizzes within five days after they were posted. The number increased to $137(86.7 \%)$ by the date of the exam. In a similar manner, the quizzes had been taken 147 times within 5 days of being published online and 409 times by the date of the exam.

It was found that the review activities conducted by the students in this work resulted in a higher average exam score $(72.67 \pm 6.85 \%)$ compared to that of the previous year $(67.73 \pm 9.50 \%)$ in which no online review activities were conducted. The course in these two years was taught to groups of students with similar learning backgrounds and profiles, by the same team of lecturers

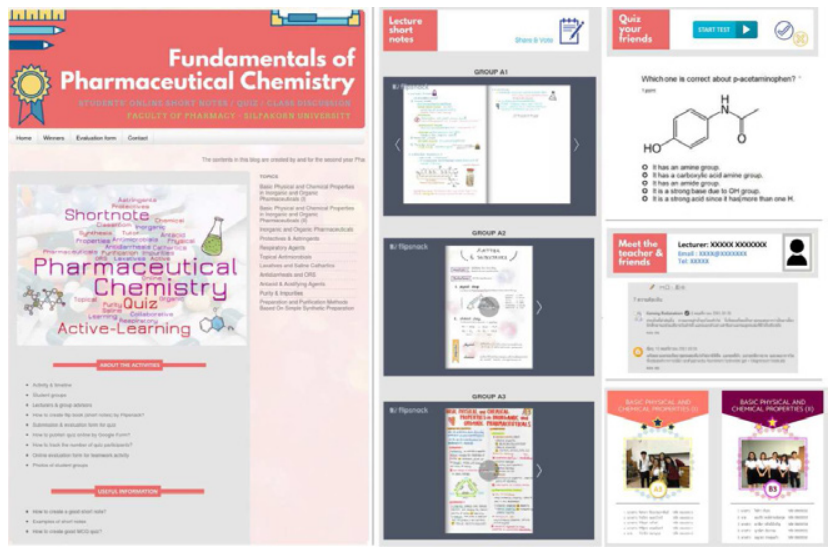

Figure 2: Weblog created and operated by students used for sharing quizzes and review notes that they generated. On this web page, blogs for discussion with lecturers and classmates as well as the hall of fame for short note contest winners were included.

and the examinations were of a similar difficulty level. The $t$-test for means and $F$-test for variance at 95\% confidence level confirmed that the participant group had a significantly higher average score $(P<.001)$ and a lower variance $(P<.001)$, which indicated a narrow distribution of scores from the mean value. In the academic staffs' opinion, the activities were beneficial and promoted active learning, leading to a better understanding of contents. In addition, the collaborative activities enhanced student responsibility by stimulating them to actively complete their work with a good quality and in a timely manner for the team's success. The responses to the Likert scale questionnaires answered by 156 students $(98.7 \%$ response rate) are presented in Table 1.

\section{DISCUSSION}

Student-generated review notes and questions are a useful and effective way of learning. It not only promotes active learning, engages students by making them co-creators of learning resources and improves understanding and memory of the lecture contents, but also helps teachers to assess the level of students' knowledge and expose misconceptions. When this strategy is used with online tools, students can participate in the activity anywhere and at any time. In this work, weblog, Google Form and flipbook were used for student-run activities since they are the tools which are familiar to most students and are easily managed without the need for programming skills. Blogs are capable of displaying text, images, embedded objects as well as links to other websites and of providing a means of communication among teachers and learners through comments or discussion posts. ${ }^{15,17}$ In addition, they are free of charge, rendering 
Table 1: Student opinion towards the activities ( $n=156$ out of 158). The score is ranked from $\mathbf{5}=$ strongly agree to $1=$ disagree).

\begin{tabular}{|c|c|}
\hline Statement & $\begin{array}{l}\text { Score } \\
\text { (out of 5) }\end{array}$ \\
\hline 1. The activities are interesting and convenient way of reviewing contents. & $4.66 \pm 0.53$ \\
\hline 2. The activities help me to review the contents faster and more direct to the main points. & $4.58 \pm 0.59$ \\
\hline 3. Creating reviewing notes enhances understanding of contents. & $4.49 \pm 0.64$ \\
\hline 4. Generating quizzes enhances understanding of contents. & $4.58 \pm 0.59$ \\
\hline 5. Taking quizzes enhances understanding of contents. & $4.59 \pm 0.57$ \\
\hline 6. The activities enhance skills in using information technology for learning. & $4.51 \pm 0.64$ \\
\hline 7. The activities enhance creativity and skill in content conclusion. & $4.55 \pm 0.55$ \\
\hline 8. The activities enhance teamwork skill. & $4.48 \pm 0.62$ \\
\hline 9. From the activities, I perceive the benefits of collaborative learning by sharing knowledge. & $4.47 \pm 0.61$ \\
\hline 10. Overall, the activities are useful and they are capable of stimulating my active learning. & $4.63 \pm 0.52$ \\
\hline 11. Overall, I am satisfied with the activities. & $4.48 \pm 0.62$ \\
\hline 12. I learn and understand how to set up the cooperative online review activity. & $4.53 \pm 0.62$ \\
\hline 13. I am confident that I and my friends are able to set up collaborative online review activity in other courses. & $4.47 \pm 0.70$ \\
\hline $\begin{array}{l}\text { Examples of opinion and suggestions; } \\
\text { - Teaching me to write and use blog is very useful in this IT and digital era. } \\
\text { - Thank you for guiding us to run this review activity ourselves. } \\
\text { - I do like it. Taking quiz after reading short notes helps me check myself and enhance the understanding and } \\
\text { memory. } \\
\text { - There should be more review questions to cover the contents. } \\
\text { - I am happy when I found the quiz in the exam. } \\
\text { - I am happy to work with my friends, instead of reading alone, to make review materials for us. } \\
\text { - The activities can stimulate me to actively learn and review the lessons. } \\
\text { - It provides me with a new and attractive way of learning. If possible, VDO should be added to blog. } \\
\text { - This is a good collaborative activity in our class and should be continued next year. } \\
\text { - It motivated my concentration on the topic I was assigned to do the best job. } \\
\text { - Some tasks are rather difficult for me at first since I am not familiar to using blog, but it finally helps me improve } \\
\text { my IT skills. } \\
\text { - My teamwork skills improved. I understand the contents better from being creator and user of review materials. } \\
\text { - Excellent! It helps me arrange a lot of contents more effectively. } \\
\text { - I very agreed with these learning activities and wish to try setting up them in other subjects. }\end{array}$ & \\
\hline
\end{tabular}

them accessible to students for conducting activities themselves. After being introduced to the instructions on how to use these tools, the students were able to effectively use them with ease.

From the teacher's evaluation of student-generated materials, the students could create clear and wellarranged content summary notes with creative and attractive designs. The quizzes produced by students were generally found to be of an acceptable quality although they were not as good as summary notes. It was likely that forming questions is a more difficult task and usually requires a deeper level of understanding than summarizing the contents when producing short notes. ${ }^{12,13}$ In addition, the majority of quizzes were made up of recall questions, probably due to the nature of the course which is the first pharmaceutical chemistry course that students take and in which students are mainly expected to be able to remember and understand the contents according to Bloom's Taxonomy of learning levels. In order to produce good quizzes, peer review with feedback by teachers was found to be necessary for the improvement of the quality of some questions prior to their release to the class, especially in terms of the relevance to the main ideas and learning objectives as well as for the promotion of a higher level of understanding than just recalling. After being published on the blog, notes and quizzes were well received by the class. About $60 \%$ of students took a quiz within 5 days of lectures. The number of quiz takers as well as the number of times that quizzes were taken increased considerably during the week before the exam. This finding indicates that the students not only used the quizzes for reviewing the contents immediately after lectures, but also in preparing for the exam.

In terms of learning effectiveness, it is clear that the activities resulted in an academic improvement since a significantly higher average exam score was found in the participant group, compared to that of non-participants 
in the previous year. Moreover, the narrow distribution of the scores (i.e. a lower standard deviation) found in the participant group implied that cooperative learning was more effective in promoting students to learn and move forward together than individual learning. In addition to enhancing the students' understanding of the course contents, the activities helped to develop $21^{\text {st }}$ century skills including creativity, teamwork and the use of information technology (IT).

Although forming questions was not an easy task for some students since they were not accustomed to it, there were no complaints raised about this issue during the study. It is possible that group activities, rather than individual work, as well as the supportive environment in which the students worked, including the provision of advice and peer assessment, assisted them to perform the tasks with less anxiety. This support also resulted in a high level of student satisfaction and positive attitudes towards the entire set of activities with most students perceiving the benefits gained from the activities. Finally, the students indicated that from the activities they ran on this course, they had learned and understood the concept, process and technical details they would need to operate the activity again. Therefore, they were confident that they could use their experiences to set up and run this kind of cooperative learning themselves, along with support from instructors, in other courses in the future.

\section{Challenges and Future Perspectives}

The results of this study have shown that students have a high level of capability in operating self-learning activities. In an era where digital technology is prevalent, students have shown an eagerness to learn how to harness these tools for use in their learning and development in a way which is compatible with their modern lifestyle. The online review activities performed by students in this study were carried out following face-to-face lectures; however they could also be used in conjunction with online lectures and exams. When considering the possible application of this method, it should be noted that it relies on technology which is always fast moving and evolving, quickly leaving older technology out-ofdate. It is also necessary to bear in mind that technology available varies in different educational institutions and in different geographic areas. Therefore, it is important for teachers to search for and introduce students to the most appropriate technological platforms available so that students can see the value in employing technology in self-learning.

\section{CONCLUSION}

Student-generated and shared review materials on an online platform is an effective means of cooperative lesson reviewing which helps students to improve learning and to develop skills such as teamwork, creativity and IT usage. In addition, it promotes a knowledge sharing environment. By giving students the opportunity of learning how to organize activities and providing them with appropriate support, this exercise can be shifted from a teacher-organized to a studentrun activity. Furthermore, once students understand, have positive attitudes and perceive the benefits they gain from the activity, it is possible for them to transfer their experiences to organize the activity themselves as desired in other courses.

\section{ACKNOWLEDGEMENT}

We are grateful for financial support from the Centre for Educational Innovation, Silpakorn University. We would like to thank the academic staff in the Department of Pharmaceutical Chemistry, Faculty of Pharmacy, Silpakorn University for their participation in these activities. Also, we acknowledge Paul Mines for his valuable help in editing and proofreading the manuscript.

\section{CONFLICT OF INTEREST}

The authors declare no conflict of interest.

\section{ABBREVIATIONS}

MCQ: Multiple choice question; IT: Information technology.

\section{REFERENCES}

1. Bovill C, Cook-Sather A, Felten P, Millard L, Moore-Cherry N. Addressing potential challenges in co-creating learning and teaching: overcoming resistance, navigating institutional norms and ensuring inclusivity in studentstaff partnerships. High Educ. 2016;71(2):195-208.

2. Arruabarrena R, Sánchez A, Blanco JM, Vadillo JA, Usandizaga I. Integration of good practices of active methodologies with the reuse of student-generated content. Int J Educ Technol High Educ. 2019;16(1):10.

3. O'Flaherty J, Phillips C. The use of flipped classrooms in higher education: A scoping review. Internet High Educ. 2015;25:85-95.

4. Akçayır G, Akçayır M. The flipped classroom: A review of its advantages and challenges. Comput Educ. 2018;126:334-45.

5. Søndergaard H, Mulder RA. Collaborative learning through formative peer review: Pedagogy, programs and potential. Comput Sci Educ. 2012;22(4):343-67.

6. Wheeler S, Yeomans P, Wheeler D. The good, the bad and the wiki: Evaluating student-generated content for collaborative learning. $\mathrm{Br} \mathrm{J}$ Educ Technol. 2008;39(6):987-95. 
7. Grainger R, Dai W, Osborne E, Kenwright D. Medical students create multiple-choice questions for learning in pathology education: A pilot study. BMC Med Educ. 2018;18(1):201.

8. Teplitski M, Irani T, Krediet CJ, DiCesare M, Marvasi M. Student-Generated Pre-Exam Questions is an Effective Tool for Participatory Learning: A Case Study from Ecology of Waterborne Pathogens Course. J Food Sci Educ. 2018;17(3):76-84.

9. Fu-Yun Y, Chia-Ling S. A student-constructed test learning system: The design, development and evaluation of its pedagogical potential. Australas $\mathrm{J}$ Educ Technol. 2015;31(6):685-98.

10. Yu FY, Chang YL, Wu HL. The effects of an online student question-generation strategy on elementary school student English learning. Res Pract Technol Enhanc Learn. 2015;10(1):24.

11. Jones JA. Scaffolding self-regulated learning through student-generated quizzes. Active Learn High Educ. 2017;20(2):115-26.

\section{PICTORIAL ABSTRACT}
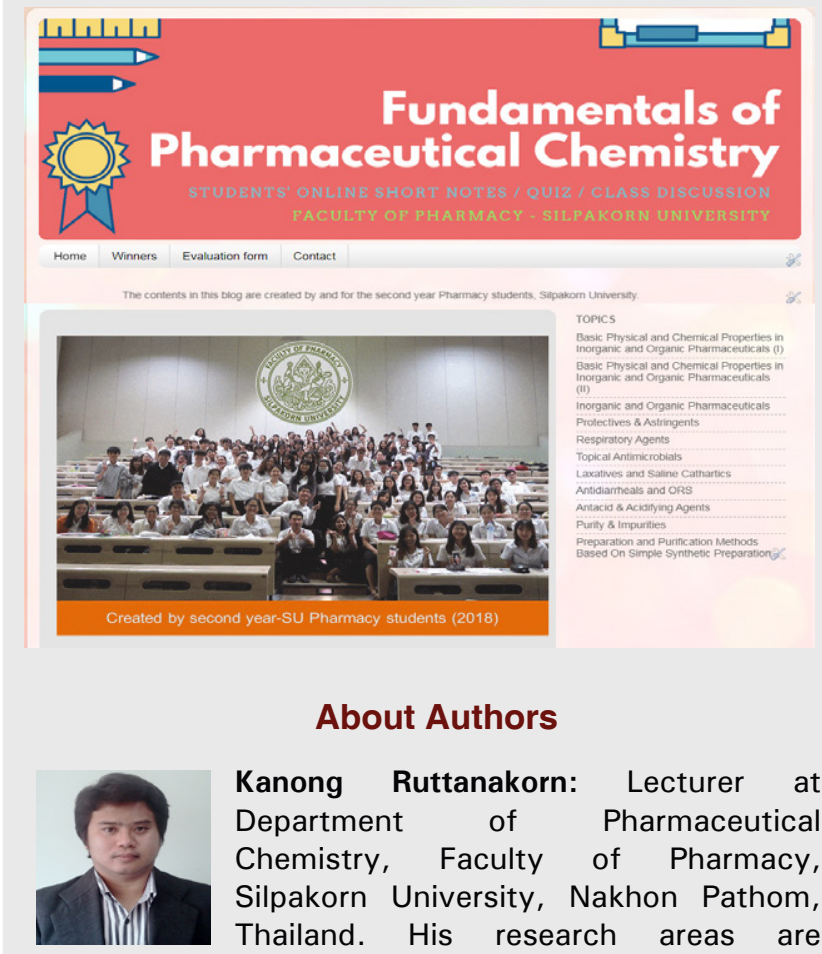

\section{About Authors}

Kanong Ruttanakorn: Lecturer at Department of Pharmaceutical Chemistry, Faculty of Pharmacy, Silpakorn University, Nakhon Pathom, Thailand. His research areas are Pharmaceutical Analysis and Pharmacy Education.

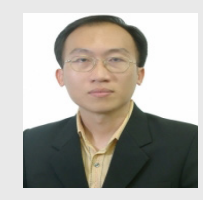

Paiboon Nuntanakorn: Assistant Professor at Department of Pharmaceutical Chemistry, Faculty of Pharmacy, Silpakorn University, Nakhon Pathom, Thailand. His research areas are Phytochemistry and Pharmaceutical Chemistry.
12. Galloway KW, Burns S. Doing it for themselves: Students creating a high quality peer-learning environment. Chem Educ Res Pract. 2015;16(1):82-92.

13. Bates SP, Galloway RK, Riise J, Homer D. Assessing the quality of a studentgenerated question repository. Phys Rev Phys Educ Res. 2014;10(2):020105.

14. Olde Bekkink M, Donders ARTR, Kooloos JG, DeWaal RMW, Ruiter DJ. Uncovering students' misconceptions by assessment of their written questions. BMC Med Educ. 2016;16(1):221.

15. Boulos MNK, Maramba I, Wheeler S. Wikis, blogs and podcasts: a new generation of Web-based tools for virtual collaborative clinical practice and education. BMC Med Educ. 2006;6(1):41.

16. Metz S, Marin P, Vayre E. The shared online whiteboard: An assistance tool to synchronous collaborative design. Eur Rev Appl Psychol. 2015.

17. Poonawalla T, Wagner R. Assessment of a blog as a medium for dermatology education. Dermatol Online J. 2006;12(1):5.

\section{SUMMARY}

With teacher support, students can effectively learn to use online platforms to collaboratively set up class review activities. In producing review materials and sharing them online for peer-use, students have shown to learn more effectively and achieve improved exam results. Besides, it promotes a knowledge sharing environment and helps develop skills such as teamwork, creativity and IT usage.

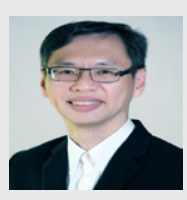

Sarayut Janmahasatian: Assistant Professor at Department of Pharmacology and Toxicology, Faculty of Pharmacy, Silpakorn University, Nakhon Pathom, Thailand. His research areas are Genetic Epidemiology, Pharmacogenomics, Comparative Effectiveness Research and Pharmacy Education.

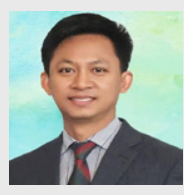

Theerasak Rojanarata: Associate Professor in Pharmaceutical Sciences at Department of Pharmaceutical Chemistry, Faculty of Pharmacy, Silpakorn University, Nakhon Pathom, Thailand. His research areas are Pharmaceutical Chemistry, Green Chemistry and Development of Innovation for Pharmacy and Chemistry Education.

Cite this article: Ruttanakorn K, Nuntanakorn P, Janmahasatian S, Rojanarata T. Promoting Student-Run Online Class Review Activities as Effective Cooperative Learning. Indian J of Pharmaceutical Education and Research. 2020;54(4):915-20. 